\title{
OPEN Treatment of symptomatic, deep, almost cariously exposed lesions using ozone
}

\author{
Mahmoud K. AL-Omiri ${ }^{1,2 \bowtie}$, Nasser M. Alqahtani ${ }^{3}$, Nasser M. Alahmari ${ }^{3}$, Raed Abul Hassan ${ }^{4}$, \\ Abdullah A. Al Nazeh ${ }^{5}$ Edward Lynch
}

The aim of this controlled randomized crossover study was to assess post-treatment pain and the need for root canal treatment after the use of a traditional caries removal method followed by restoration, or after an ozone method of more conservatively managing the deep caries and a restoration. 84 participants ( 42 males and 42 females, mean age $\pm S D=23.9 \pm 2.0$ years) were randomly allocated to receive either a traditional ( $n=42,21$ males and 21 females) or ozone ( $n=42,21$ males and 21 females) method. The ozone method only differed from the traditional method by leaving the deep leathery caries on the pulpal floor and then treating this with $20 \mathrm{~s}$ of ozone from the healozone X4 (Curozone, Germany). All caries was removed in the traditional group. A conventional glass ionomer cement (Riva Self Cure High Viscosity, SDI, Australia) was placed followed by a bonded composite resin restoration (Filtek Z250 Universal Restorative, 3 M ESPE, USA) in each cavity. The visual analogue scale was used to assess pain scores before treatment and after $24 \mathrm{~h}$. The participants were then followed up for 2 years to assess the need for root canal treatment. Statistical significance levels were set at $\alpha \leq .05$. Both groups were associated with significant reduction of pain scores $24 \mathrm{~h}$ after treatment $(p<.0001)$. The ozone treatment was associated with less pain $24 \mathrm{~h}$ after treatment $(p<.0001)$ and less need for root canal treatment $(p=.014)$, after 2 years follow up, than the conventional treatment. In conclusion, treatment of symptomatic, deep carious lesions by ozone following partial removal of caries was accompanied with less pain and occurrence of RCT after treatment compared to traditional complete caries removal.

Different treatment protocols are available to use for the management of dental caries. More interest has been instituted in management of caries using pharmaceutical agents including silver diamine fluoride and/or ozone ${ }^{1-6}$. This could decrease the need for conventional drilling and filling of carious lesions, and therefore might potentially enhance patients' acceptance and compliance with the treatment ${ }^{5}$.

Ozone treatment is among the pharmaceutically least invasive techniques utilized for caries prevention and treatment. This paradigm might be used solely or in combination with other techniques to treat carious lesions ${ }^{2,3,6-10}$. Caries management using ozone is conservative, consumes less treatment time, and requires shorter periods of mouth opening ${ }^{11}$. In addition, ozone is efficient in killing and reducing different cariogenic microorganisms (such as streptococcus mutans, streptococcus sobrinus and lactobacilli) in both clinical and laboratory settings, especially using the healozone $\mathrm{e}^{1-5,8,12-31}$.

Previous studies established that ozone treatment using the healozone could enhance the remineralization process and thus improve the hardness of open single surface shallow carious lesions $s^{4,7,28}$. However, significantly less cariogenic microorganisms and more arrested caries were associated with ozone application into small shallow carious lesions but not in very deep large ones ${ }^{2}$. It was reported that ozone application alone or in conjunction with remineralizing solutions was associated with remineralization of initial non cavitated pit, fissure, root and proximal carious lesions ${ }^{2-4,6,7,9,25,32,33}$. Ozone was also established to control open carious lesions in deciduous teeth ${ }^{26,28,34}$.

\footnotetext{
${ }^{1}$ Department of Prosthodontics, School of Dentistry, University of Jordan, Queen Rania Street, Amman 11942, Jordan. ${ }^{2}$ Department of Prosthodontics, The City of London Dental School, Canada Water, Lower Road, London, UK. ${ }^{3}$ Department of Prosthodontics, College of Dentistry, King Khalid University, Asir-Abha, Saudi Arabia. ${ }^{4}$ Faculty of Allied Medical Sciences, The Royal University for Medical Sciences, Amman, Jordan. ${ }^{5}$ Department of Pediatric Dentistry and Orthodontics Sciences, College of Dentistry, King Khalid University, Asir-Abha, Saudi Arabia. ${ }^{6}$ School of Dental Medicine, University of Nevada Las Vegas (UNLV), Las Vegas, NV, USA. ${ }^{\bowtie}$ email: alomirim@yahoo.co.uk
} 
Treatment of deep carious lesions that approach the pulp is among the most important challenges in caries management. Total caries removal might lead to tooth sensitivity, pulp exposure, or the need for indirect pulp capping, direct pulp capping, pulpotomy or pulpectomy ${ }^{35,36}$. In an attempt to reduce these complications, conservative and ultraconservative caries management protocols including stepwise caries excavation and partial caries removal were suggested in the literature ${ }^{37,38}$.

However, residual bacteria might cause pulpal inflammation, secondary caries and failure of restorations. Therefore, it was suggested to perform lesion disinfection using pharmaceutical agents (such as chlorhexidine or ozone) in order to allow lesions to repair ${ }^{29,39-41}$. Another method was to use photodynamic antimicrobial therapy (PAD) which uses a sensitizer that is absorbed by bacteria, then the lesion is exposed to light of a specific wavelength to kill the bacteria ${ }^{42}$.

The literature reported no harmful consequences of applying ozone on deep caries or exposed pulps ${ }^{2-4,27-29,34}$. Previous studies showed that ozone was more biocompatible with human oral epithelial cells and gingival fibroblasts than chlorhexidine, sodium hypochlorite, hydrogen peroxide, and metronidazole ${ }^{43}$. Ozone was found to have anti-inflammatory effects on oral cells and periodontal ligament tissues from roots of periodontally involved teeth $^{44}$. In addition, ozone was found to boost healing of traumatic and recurrent aphthous ulcers and reduce pain levels caused by ulcers ${ }^{45,46}$.

Indeed, the literature reported many positive effects of ozone on human tissues including oral tissues ${ }^{30,44-54}$. Ozone enhances the metabolism of inflamed tissues by improving blood circulation, increasing tissue oxygenation and reducing inflammation ${ }^{30,44,47-49}$. It stimulates immunity through proliferation of immune cells, release of endogenous interferon, synthesis of immunoglobulins, activation of macrophage function, and increasing sensitivity of microorganisms to phagocytosis ${ }^{30,47,48}$. It also possesses analgesic properties ${ }^{30,45-47,51-53}$.

However, studies on using ozone in the management of symptomatic deep caries after leaving some carious tissues before the final restoration of permanent dentition are scarce. Therefore, the current study was carried out to explore the use of ozone in management of symptomatic deep caries approaching the pulp in the permanent dentition.

The purpose of this study was to measure pain levels and the need for root canal treatment in teeth with deep carious lesions following using a conservative protocol of $20 \mathrm{~s}$ of ozone application on partially removed deep caries before a restoration, in comparison to a conventional treatment protocol of total caries removal and restoration.

The null hypothesis for the present study was that in symptomatic deep carious lesions approaching the pulp, $20 \mathrm{~s}$ of ozone application on partially removed deep caries before a restoration would lead to similar pain levels and need for root canal treatment as when a conventional treatment protocol of total caries removal and a restoration is followed.

\section{Materials and methods}

Eighty four participants (42 males and 42 females) were recruited into this study. The study was conducted at the dental clinics, School of Dentistry, the University of Jordan (January 2017 until March 2020). Participants age ranged from 20 to 27 years old (mean age $\pm S D=23.8 \pm 2.0$ years). This study was ethically approved by the Institutional Review Board, the University of Jordan, Amman, Jordan (Reference Number ARC-6-2015). All methods in this study were carried out in full accordance with Helsinki Declaration (9th version, 2013). This investigation was reported following the STROBE guidelines. Each potential participant was provided with a detailed explanation of the experiment, and written informed consent was obtained from each participant before inclusion in this study.

Participants were included in this experiment if they had a molar tooth with an extensive carious lesion which was causing the participants pain and which radiographically was almost cariously exposed. The involved tooth had to be vital and be sensitive to both hot and cold tests but the pain did not wake the subject up nor keep the subject awake at night. The involved tooth should not have been restored, prepared for a crown or bridge retainer, or be affected by periodontitis or extensive tooth surface loss. Participants should not have received any previous treatment for the involved carious tooth and should not have other complicating medical history. Therefore, participants who received previous treatment to the involved tooth or had their tooth affected by periodontitis or extensive tooth surface loss, or experience complicating medical history were excluded from this experiment. Participants were also excluded if they presented with temporomandibular joint problems, sinusitis, oral ulceration or any loss of lamina dura on their periapical radiograph. In addition, pregnant/lactating women were excluded from this experiment.

After recruitment, the participants were randomly distributed into two groups ( $\mathrm{n}=42$ for each group). A simple randomization procedure was applied using computer generated numbers with gender stratification to avoid sex-based bias following previous recommendations $\mathrm{s}^{45,55}$.

Each participant was thoroughly examined on a dental chair supplied with a light unit (Diamond LED Dental Light; Daray Lighting, Derbyshire, England, UK). The involved tooth was dried prior to examination. A dental mirror (15/16 inch; Hahnenkratt, Königsbach-Stein, Germany) and an explorer probe (0700-9, anatomical handle single ended; ASA Dental, Bozzano, Italy) were utilized during the intra-oral examinations. Tooth vitality was evaluated via an ice stick and compared to the response of other teeth. A pre-operative periapical digital radiograph (Ez Sensor, Vatech, Korea) was taken for the involved tooth to check for caries extension as well as to assess the periodontal and periapical conditions of the involved tooth.

Subsequently, participants' tooth pain was assessed using a visual analogue scale (VAS) score from 0 (no tooth pain at all) to 10 (tooth pain as bad as imaginable).

A rubber dam (Sanctuary Powder Free Latex Dental Dam, 6" $\times 6$ " size, Sanctuary Health, Malaysia) was used with all participants during treatment of the involved teeth. In group 1 , the carious lesions were treated by partial 
removal of caries under copious water irrigation using diamond burs (Edenta, Switzerland) mounted on contraangled high speed handpiece (Coxo CX207-B, COXO Medical Instrument Co., China) and finally tungsten carbide burs mounted on a slow speed handpiece (Gold-U-CA, AppleDental, China). About $1 \mathrm{~mm}$ thickness of the deep leathery caries was left on the pulpal floor depending on measurements from preoperative periapical digital radiograph. Also, it was required that the remaining caries was leathery as determined by having resistance to withdrawal after being penetrated by a sharp explorer using light probing pressure (similar to the pressure used during probing depth measurements). Then, ozone gas (concentration of $2350 \mathrm{ppm}$ and a flow rate of $615 \mathrm{cc} / \mathrm{min}$ ) was applied via the healOzone X4 machine (Curozone, Germany) for $20 \mathrm{~s}$ to disinfect the remaining leathery dentine caries. Ozone gas was delivered to the carious lesions using disposable silicone cups purchased from the manufacturer, and used to secure an adequate seal to prevent any ozone leakage. After that, the pulpal floor and adjacent wall of each cavity were covered by a glass ionomer cement (Riva Self Cure High Viscosity, SDI, Australia) followed by a bonded composite resin restoration (Filtek Z250 Universal Restorative, 3 M ESPE, USA; Single Bond Universal Adhesive, 3 M ESPE, Germany; Ultra-Etch 35\% phosphoric acid, Ultradent, USA).

In contrast, carious lesions in group 2 were treated traditionally by a total removal of caries under copious water irrigation using diamond burs (Edenta, Switzerland) mounted on a contra-angled high speed handpiece (Coxo CX207-B, COXO Medical Instrument Co., China) and then with tungsten carbide burs mounted on a slow speed handpiece (Gold-U-CA, AppleDental, China) before placement of the glass ionomer cement (Riva Self Cure High Viscosity, SDI Australia) followed by composite restoration (Filtek Z250 Universal Restorative, 3 M ESPE, USA; Single Bond Universal Adhesive, 3 M ESPE, Germany; Ultra-Etch 35\% phosphoric acid, Ultradent, USA).

After restoration, the participants were instructed to attend $24 \mathrm{~h}$ later for review and further assessment of pain. Participants' tooth pain was assessed using the same VAS score.

The restored teeth in both groups were assessed on a weekly basis for 1 month then each month for 6 months. Then, they were assessed every 6 months till the end of the study. On each recall visit, the teeth were assessed for vitality, tenderness to percussion, swelling or change in colour. Assessment for the need for endodontic treatment was carried out by evaluation of tooth vitality using cold ice sticks and comparison to other teeth. The participants were instructed to report to the clinic if they feel any symptoms related to the restored tooth such as swelling or spontaneous pain that woke the participant up or keep them awake at night.

In this study, tooth restoration was carried out by one investigator (M.K.AL-O), meanwhile pain assessment and need for endodontic treatment was assessed via another investigator (R.A.H) who was blinded to the performed restoration protocol. Intra-examiner reliability was verified through evaluating 15 duplicate pain assessments by the same investigator, and Kappa was found to be adequate $(\kappa=0.92)$.

Statistical analysis. Data analysis was performed using the SPSS computer software (Statistical Package for the Social Sciences, v19.0; IBM, Armonk, NY, USA). The Kolmogorov-Smirnov test was used to test normal distribution of the data. The Spearman correlation test was utilized to explore the relationships between age on one side and the pain scores at baseline, pain scores $24 \mathrm{~h}$ after restoration, and the need for RCT. The Fisher's Exact test was used to explore the relationship between the need for RCT and pain scores. The Mann Whitney test was used for comparisons between males and females within each group. The Mann Whitney test was also used for comparisons between ozone and conventionally treated groups. The statistical significance for this study was set at probability values of $\mathrm{P} \leq 0.05$ and a $95 \%$ confidence interval.

The hierarchical multiple regression analysis considering the confounding effects of gender, age, and treated tooth was utilized to identify the contribution of the treatment protocol towards the VAS pain scores after $24 \mathrm{~h}$ of treatment. Also, the hierarchical multiple logistic regression analysis considering the confounding effects of gender, age, and treated tooth was utilized to identify the contribution of the treatment protocol towards the need for RCT throughout the study period.

For this experiment, the sample size was calculated via the $\mathrm{G}^{\star}$ Power 3.1.9.7 software (Heinrich-Heine-University, Düsseldorf, Germany). The minimum sample size was estimated to be 34 participants per group utilizing a priori power analysis with a significance level of 5\%, a statistical power of $80 \%$, and an effect size of $20 \%$. Therefore, 42 participants per group were recruited into this experiment to compensate for any possible dropouts.

\section{Results}

The study population consisted of 84 participants ( 42 females and 42 males). The data from all included participants was analyzed. None of the participants were lost to follow up (drop out ratio was zero \%). Participants age ranged between 20 and 27 years old (mean age $=23.92$ years old, $\mathrm{SD}= \pm 2.01$ years, $\mathrm{SE}= \pm 0.22$ years).

The mean pain visual analogue scale score for participants with the traditional treatment was 7.98 (SD \pm 0.78 , $95 \% \mathrm{CI}=7.73-8.22, \mathrm{SE}=0.120)$ before treatment and $5.40(\mathrm{SD} \pm 1.62,95 \% \mathrm{CI}=4.90-5.91, \mathrm{SE}=0.251)$ after $24 \mathrm{~h}$ whilst these were $7.76(\mathrm{SD} \pm 0.76,95 \% \mathrm{CI}=7.53-8.00, \mathrm{SE}=0.117)$ and $0.52(\mathrm{SD} \pm 0.99,95 \% \mathrm{CI}=0.21-0.83$, $\mathrm{SE}=0.153)$ for the ozone treated participants. After 2 months, $8(19.0 \%)$ participants required root canal treatment from the traditional management group whilst $1(2.4 \%)$ participant required root canal treatment in the ozone group. Gender distributions of pain scores and the need for RCT are presented in Table 1.

After 2 years follow up, 8 participants required root canal treatment from the traditional management group whilst 1 participant required root canal treatment in the ozone group. Among the traditional group, one participant required root canal treatment 3 days after filling, 2 participants after one week, 3 participants after two weeks, and 2 participants after four weeks following restoration. However, only one participant required root canal treatment after 1 week among the ozone group.

In the ozone group, age was not related to pain scores before treatment (Spearman correlation $=-0.135$, $\mathrm{p}=0.394$ ), pain scores after $24 \mathrm{~h}$ (Spearman correlation $=-0.065, \mathrm{p}=0.685)$, and the need for RCT (Spearman 


\begin{tabular}{|c|c|c|c|c|c|c|c|}
\hline \multirow[b]{2}{*}{ Variables } & \multicolumn{2}{|c|}{ Ozone group } & \multicolumn{2}{|c|}{ Traditional group } & \multicolumn{3}{|c|}{ Mann Whitney test } \\
\hline & Males & Females & Males & Females & MW-U & $\mathrm{Z}$ & $\mathbf{P}$ \\
\hline \multicolumn{5}{|c|}{ Tooth pain at baseline } & \multirow{5}{*}{163.0} & \multirow{5}{*}{-1.562} & \multirow{5}{*}{.118} \\
\hline Mean & 7.57 & 7.95 & 8.05 & 7.90 & & & \\
\hline SD & 0.746 & 0.740 & 0.740 & 0.831 & & & \\
\hline CI & $7.23-7.91$ & $7.62-8.29$ & $7.71-8.38$ & $7.53-8.28$ & & & \\
\hline SE & 0.163 & 0.161 & 0.161 & 0.181 & & & \\
\hline \multicolumn{5}{|c|}{ Tooth pain after $24 \mathrm{~h}$} & & & \\
\hline Mean & 0.33 & 0.71 & 5.57 & 5.24 & \multirow{4}{*}{185.5} & \multirow{4}{*}{-1.028} & \multirow{4}{*}{.304} \\
\hline SD & 0.483 & 1.309 & 1.599 & 1.670 & & & \\
\hline $\mathrm{CI}$ & $0.11-0.55$ & $0.12-1.31$ & $4.84-6.30$ & $4.48-6.00$ & & & \\
\hline SE & 0.105 & 0.286 & 0.349 & 0.365 & & & \\
\hline \multicolumn{5}{|c|}{ Need for RCT } & & & \\
\hline Frequency & 0 & 1 & 4 & 4 & 210.0 & -1.000 & .317 \\
\hline
\end{tabular}

Table 1. Differences between genders regarding baseline pain scores, pain scores after $24 \mathrm{~h}$ of treatment, and the need for root canal treatment within each study group. MW-U = Mann Whitney $\mathrm{U}$ test coefficient, $\mathrm{Z}=\mathrm{Z}$ statistic, $\mathrm{P}=$ two tailed probability, $\mathrm{SD}=$ Standard deviation, $\mathrm{CI}=95 \%$ Confidence intervals of the mean, $\mathrm{SE}=$ Standard error of the mean, $\mathrm{RCT}=$ Root canal treatment.

\begin{tabular}{|l|l|l|l|}
\hline Statistics & Tooth pain at baseline & Tooth pain after $\mathbf{2 4} \mathbf{h}$ & Need for RCT \\
\hline MW-U & 758.0 & 28.5 & 735.0 \\
\hline Z & -1.187 & -7.787 & -2.455 \\
\hline P & .235 & $<.0001$ & .014 \\
\hline
\end{tabular}

Table 2. Differences of dental pain and the need for root canal treatment between ozone and traditional treatment groups $(\mathrm{n}=84,42$ participants for each group). $\mathrm{MW}-\mathrm{U}=$ Mann Whitney $\mathrm{U}$ test coefficient, $\mathrm{Z}=\mathrm{Z}$ statistic, $\mathrm{P}=$ Two tailed probability, $\mathrm{RCT}=$ Root canal treatment.

correlation $=-0.046, p=0.774)$. Also in the traditional group, age was not related to pain scores before treatment (Spearman correlation $=0.158, \mathrm{p}=0.319)$, pain scores after $24 \mathrm{~h}($ Spearman correlation $=0.001, \mathrm{p}=0.996)$, and the need for RCT (Spearman correlation $=-0.041, \mathrm{p}=0.798$ ).

In both groups, it was found that gender had no significant relationship with pain scores at baseline, pain scores $24 \mathrm{~h}$ after restoration, or the need for RCT $(\mathrm{p}>0.05)$ (Table 1$)$.

The need for RCT was not related to the pain scores at study baseline before ozone (Fisher's Exact test value $=5.494, \mathrm{p}=0.190$ ) as well as traditional intervention (Fisher's Exact test value $=4.786, \mathrm{p}=0.091$ ). On the other hand, the need for RCT was significantly related to pain scores $24 \mathrm{~h}$ after restoration among the ozone group (Fisher's Exact test value $=9.069, \mathrm{p}=0.024$ ) as well as traditional treatment group (Fisher's Exact test value $=27.537, \mathrm{p}<0.0001$ )

Mann Whitney test showed significant differences between groups in terms of VAS scores of pain after $24 \mathrm{~h}$ of treatment $(\mathrm{p}<0.0001)$ and the need for RCT after 2 years follow up $(\mathrm{p}=0.014)$ (Table 2). Ozone treatment was associated with less pain and less need for RCT.

The hierarchical multiple regression analysis considering the confounding effects of gender, age, and treated tooth revealed that the treatment protocol has significant contribution towards the VAS pain scores after $24 \mathrm{~h}$ of treatment $(\mathrm{p}<0.0001)$ (Table 3). Also, the treatment protocol has significant contribution towards the need for RCT after 2 years follow up $(\mathrm{p}=0.038)$ (Table 4$)$.

\section{Discussion}

The outcomes of this study showed that in symptomatic deep carious lesions approaching the pulp, 20 s of ozone application on partially removed deep caries before a restoration would lead to less pain levels and less need for endodontic treatment in comparison to a conventional treatment protocol of total caries removal and a restoration. Therefore, the null hypothesis was rejected.

In this experiment, the healozone machine was utilized to supply ozone because it has been shown to be safe since its ozone releasing system is effectively sealed before the machine generates ozone ${ }^{56,57}$. Ozone gas is delivered to the tooth using different sizes of disposable silicone cups supplied by the manufacturer and these guarantee a perfect seal to avoid ozone leakage. Each cup is pressed against the tooth in order to ensure that the maximum ozone is delivered directly into the tooth. Furthermore, application of ozone via the healozone machine is better than many other ozone or other pharmaceutical application techniques as it only functions locally and not on large areas like mouth washes, and therefore does not negatively impact on the oral cavities resident protective microflora. 


\begin{tabular}{|c|c|c|c|c|c|c|c|c|}
\hline \multirow[b]{2}{*}{ Model $^{*}$} & \multirow[b]{2}{*}{ Predictors } & \multicolumn{2}{|c|}{ Unstand Co } & \multirow{2}{*}{\begin{tabular}{|l|} 
Stand Co \\
Beta
\end{tabular}} & \multirow[b]{2}{*}{$\mathrm{t}$} & \multirow[b]{2}{*}{ Sig } & \multicolumn{2}{|l|}{ 95\% CI for B } \\
\hline & & B & SE & & & & Lower bound & Upper bound \\
\hline \multirow{4}{*}{$\begin{array}{l}\text { Model } 1 \\
\mathrm{R}^{2}=.008\end{array}$} & (Constant) & 4.753 & 3.930 & - & 1.209 & .230 & -3.068 & 12.574 \\
\hline & Gender & .087 & .624 & .016 & .140 & .889 & -1.155 & 1.329 \\
\hline & Age & -.094 & .157 & -.067 & -.597 & .552 & -.405 & .218 \\
\hline & Affected tooth & .133 & .284 & .053 & .471 & .639 & -.431 & .698 \\
\hline \multirow{5}{*}{$\begin{array}{l}\text { Model } 2 \\
\mathrm{R}^{2}=.771\end{array}$} & (Constant) & -4.475 & 1.981 & - & -2.258 & .027 & -8.418 & -.531 \\
\hline & Gender & .035 & .301 & .006 & .116 & .908 & -.565 & .635 \\
\hline & Age & -.002 & .076 & -.002 & -.030 & .976 & -.153 & .149 \\
\hline & Affected tooth & .054 & .137 & .021 & .393 & .695 & -.219 & .327 \\
\hline & Treatment protocol & 4.875 & .300 & .877 & 16.246 & $<.0001$ & 4.278 & 5.472 \\
\hline
\end{tabular}

Table 3. Hierarchical multiple regression analysis to predict the contribution of the treatment protocol towards the VAS pain scores after $24 \mathrm{~h}$ of treatment $(n=84) . \mathrm{R}^{2}=$ Coefficient of determination, Unstand $\mathrm{Co}=$ Unstandardized coefficient, Stand $\mathrm{Co}=$ Standardized coefficient, $\mathrm{B}=$ Beta statistics, $\mathrm{SE}=$ Standard Error, $\mathrm{t}=\mathrm{t}$ statistics, $\mathrm{Sig}=$ Significance of probability $(\mathrm{P}$ value $), \mathrm{CI}=$ Confidence intervals. ${ }^{*}$ Significance of $\mathrm{F}$ statistic change was $\mathrm{P}=.886$ and $\mathrm{P}<.0001$ for Model 1 and Model 2 respectively.

\begin{tabular}{|c|c|c|c|c|c|c|c|}
\hline \multirow[b]{2}{*}{ Variable blocks ${ }^{*}$} & \multirow[b]{2}{*}{ B } & \multirow[b]{2}{*}{ SE } & \multirow[b]{2}{*}{ df } & \multirow[b]{2}{*}{ Sig } & \multirow[b]{2}{*}{$\operatorname{Exp}(B)$} & \multicolumn{2}{|c|}{$\operatorname{Exp}(B) 95 \% \mathrm{CI}$} \\
\hline & & & & & & Lower & Upper \\
\hline \multicolumn{8}{|c|}{ Block 1 (Nagelkerke $R^{2}=.011$. Hosmer and Lemeshow test probability value $\left.(P)=.594\right)$} \\
\hline Gender & .313 & .727 & 1 & .667 & 1.368 & .329 & 5.686 \\
\hline Age & -.041 & .179 & 1 & .819 & .960 & .675 & 1.364 \\
\hline Affected tooth & .170 & .325 & 1 & .601 & 1.185 & .627 & 2.240 \\
\hline Constant & -2.035 & 4.388 & 1 & .643 & .131 & - & - \\
\hline \multicolumn{8}{|c|}{ Block 2 (Nagelkerke $R^{2}=.166$. Hosmer and Lemeshow test probability value $\left.(P)=.385\right)$} \\
\hline Gender & .312 & .751 & 1 & .678 & 1.366 & .314 & 5.948 \\
\hline Age & -.019 & .198 & 1 & .925 & .982 & .665 & 1.448 \\
\hline Affected tooth & .158 & .343 & 1 & .646 & 1.171 & .598 & 2.293 \\
\hline Treatment protocol & 2.257 & 1.088 & 1 & .038 & 9.551 & 1.133 & 80.507 \\
\hline Constant & -6.383 & 5.241 & 1 & .223 & .002 & - & - \\
\hline
\end{tabular}

Table 4. Prediction of the contribution of treatment protocol towards the need for root canal treatment among the study population using the hierarchical logistic regression analysis $(n=84)$. B = the B coefficient of the model, $\mathrm{SE}=$ Standard error $\mathrm{df}=$ Degree of freedom, Sig. = Significance of two tailed probability value $(\mathrm{P})$, $\operatorname{Exp}(\mathrm{B})=$ Exponentiated $\mathrm{B}$ coefficients, $\mathrm{CI}=$ Confidence intervals. ${ }^{\star}$ The predicted overall percentage for each Block equals $89.3 \%$.

The outcomes of this experiment showed that pain levels after $24 \mathrm{~h}$ following restoration were less within the ozone treated group. This could be partly due to the known analgesic characteristics of ozone ${ }^{45,47,51-53,58,59}$.

Ozone has been found to decrease pain ${ }^{30,45,47,51-53,60-62}$, decrease tooth sensitivity ${ }^{51-53,60,61}$, and boost regeneration and improve healing ${ }^{30,45-47,60-62}$.

Also, previous studies showed that ozone reduces pain caused by lumbar disc herniation ${ }^{63}$. It also possesses strong anti-inflammatory and anti-oxidant effects against oxidative stress-induced tissue injuries ${ }^{50}$. Furthermore, ozone enhances the activity of antioxidant enzymes (including glutathione peroxidase, superoxide dismutase, and catalase) which combat inflammation ${ }^{30,47,50}$. In addition, it restrains inflammatory pathways by reducing prostaglandin production and inactivating cyclooxygenase ${ }^{54}$.

Reduced tooth pain after ozone application might also be attributed to reduction in number and diameter of open dentinal tubules ${ }^{64,65}$ and collagen degradation ${ }^{66}$ which might potentially block the dentinal tubules mechanically.

This is in agreement with the results of previous studies that reported less pain when ozone was used for other dental and oral applications such as treatment of recurrent oral ulcers, treatment of denture induced ulcers, extraction of third molars, management of jaw osteonecrosis, dentine hypersensitivity treatment, and bleaching ${ }^{45,46,51-53,67-69}$.

Besides, the findings of this experiment demonstrated that ozone treatment of deep caries was associated with less need for RCT than conventional treatment. This could also be attributed to the fact that ozone is effective for killing cariogenic microorganisms ${ }^{1-5,8,12-27,29}$.

Also, ozone prevents formation of bacterial biofilms on dentine by changing dentine wettability through oxidation of organic elements (such as proteins, carbohydrates, glycolipids and acids) ${ }^{8,12,17,30,31}$. 
Nevertheless, ozone has limits to the distance it can infiltrate into a carious lesion. Previous researchers found that ozone did not decrease bacterial count in very deep large carious lesion or deep non cavitated lesion ${ }^{2,5}$. This indicates that direct contact between ozone and caries is required to achieve the desired outcomes as the ozone needs to penetrate the lesion to be effective.

For that reason, direct ozone application into open cavities following partial caries removal leaving only about one $\mathrm{mm}$ of caries was the tested treatment protocol in this experiment.

Also, ozone has beneficial effects on the pulp and can neutralize toxic endotoxins that irritate the pulp, and thus help the pulp to recover. As discussed before, ozone has strong anti-inflammatory and anti-oxidant properties against oxidative stress-induced tissue injuries ${ }^{47,50}$. Moreover, ozone boosts the activity of antioxidant enzymes (including glutathione peroxidase, superoxide dismutase, and catalase) which counteract inflammation ${ }^{30,47,50}$. Additionally, it controls inflammatory pathways by decreasing prostaglandin release and inactivating cyclooxygenase $\mathrm{e}^{54}$.

The above discussion corroborate the anti-inflammatory, anti-oxidative and analgesic merits of ozone for dental pulp tissues ${ }^{49}$, and this would explain the efficiency of ozone in boosting healing and avoiding injury of pulp tissues.

This is in agreement with previous findings that ozone application after partial removal of caries from deep carious lesions in deciduous teeth would avoid the need for pulpotomy and result in success rates similar to pulpotomy $^{34}$.

Also, other researchers found that ozone treatment either alone or combined with a re-mineralizing agent was efficient for remineralization of shallow as well as initial pit, fissure, root and proximal carious lesions in permanent and deciduous teeth ${ }^{4,6,7,9,25,26,28,32,33}$. The oxidative capacity of ozone allow destruction of the substances that demineralise dental tissues and prevent remineralization (such as formic, lactic, and pyruvic organic acids) $)^{1,29}$. Ozone was also found to reduce the number of microorganisms in deep carious lesions, and was associated with drier and harder dentine consistency ${ }^{70-72}$.

With the current findings in mind, it is useful to use ozone for management of deep caries as this would potentially reduce pain and the need for RCT, hence potentially improve patients' compliance with caries treatment. If one is to leave some deep caries in an attempt not to expose the pulp, it would certainly seem more logical to aim to kill the acidogenic and aciduric microorganisms in the deep caries before placing any restoration. In addition, ozone treatment of deep caries might allow a less invasive approach for caries management that permits treatment of the cause of dental caries and help dental professionals to avoid root canal treatment in many cases.

Previous reports concluded that using ozone for management of caries was also associated with less patient anxiety ${ }^{28,73}$. Furthermore, a side gain of ozone application is that it does enhance the colour of teeth ${ }^{51-53,74-77}$. After all, ozone is adequately controlled via the dentist since the healozone machine permits adequate control of delivery site, concentration, volume and flow rates of ozone. Moreover, ozone application is rapid, convenient, less costly, and not irritant to dental tissues.

A limitation of this study was that the current experiment tested immediate and short-term effects of ozone application on deep carious lesions.

Future long term investigations are urged on larger samples to evaluate the effects of ozone for management of deep carious lesions approaching the pulp.

Furthermore, studies are requested to investigate the potential effectiveness of ozone in treatment of deep caries in comparison to other deep caries management techniques. Also, future studies are required to compare ozone and SDF for management of caries. In addition, future studies are needed to explore dentists' views and patients' compliance and satisfaction with using ozone for deep caries management in comparison to other techniques.

Further studies are also requested to achieve definite conclusions concerning whether adequate cavity sealing would result in death of viable bacteria left beneath tooth filling. Moreover, to discover whether it is required to disinfect dentine before restoration and which are the best techniques to disinfect residual dentine. Some researchers reported that leaving infected dentine and simply sealing cavity with restoration was a successful treatment paradigm for deep caries ${ }^{77-80}$.

However, other researchers have demonstrated caries progression when caries was sealed in without disinfection ${ }^{81-83}$. In order to resolve this controversy, a future study is planned with 2 groups, leaving about $1 \mathrm{~mm}$ of caries in each; one using ozone to disinfect dentine and the other not using ozone and simply sealing in the caries.

\section{Conclusion}

This study concluded that ozone treatment of symptomatic teeth with deep, carious lesions almost reaching the pulp shows promise for a more conservative approach to treat deep caries as well as being associated with less postoperative pain and less need for root canal treatment compared to a traditional method.

\section{Data availability}

Data generated and analysed during this study are available from the corresponding author upon request to the following email: alomirim@yahoo.co.uk.

Received: 8 March 2021; Accepted: 12 May 2021

Published online: 27 May 2021 


\section{References}

1. Baysan, A., Whiley, R. \& Lynch, E. Anti-microbial effects of a novel ozone generating device on micro-organisms associated with primary root carious lesions in vitro. Caries Res. 34, 498-501 (2000).

2. Baysan, A. \& Lynch, E. Effect of ozone on the microbial flora and clinical severity of primary root caries. Am. J. Dent. 17, 56-61 (2004).

3. Baysan, A. \& Lynch, E. The use of ozone in dentistry and medicine, 2: ozone and root caries. Prim. Dent. Care 13, 37-41 (2006).

4. Baysan, A. \& Lynch, E. Clinical reversal of root caries using ozone: 6-month results. Am. J. Dent. 20(4), 203-208 (2007).

5. Baysan, A. \& Beighton, D. Assessment of the ozone-mediated killing of bacteria in infected dentine associated with non-cavitated occlusal carious lesions. Caries Res. 41, 337-341 (2007).

6. Reddy, S. A., Reddy, N., Dinapadu, S., Reddy, M. \& Pasari, S. Role of ozone therapy in minimal intervention dentistry and endodontics-a review. J. Int. Oral Health 5(3), 102-108 (2013).

7. Holmes, J. Clinical reversal of root caries using ozone, double-blind, randomised, controlled 18-month trial. Gerodontology 20(2), 106-114 (2003).

8. Huth, K. C., Paschos, E., Brand, K. \& Hickel, R. Effect of ozone on non-cavitated fissure carious lesions in permanent molars: a controlled prospective clinical study. Am. J. Dent. 18, 223-228 (2005).

9. Atabek, D. \& Oztas, N. Effectiveness of ozone with or without the additional use of remineralizing solution on non-cavitated fissure carious lesions in permanent molars. Eur. J. Dent. 5(4), 393-399 (2011).

10. Tahmassebi, J. F., Chrysafi, N. \& Duggal, M. S. The effect of ozone on progression or regression of artificial caries-like enamel lesions in vitro. J. Dent. 42(2), 167-174 (2014).

11. Abu-Salem, O., Marashdeh, M., Holmes, J., Lynch, E. Clinical management of deciduous caries using ozone. In: Ozone -The Revolution in Dentistry (ed. Lynch, E.) 189-198 (Quintessence, 2004).

12. Nagayoshi, M. et al. Efficacy of ozone on survival and permeability of oral microorganisms. Oral Microbiol. Immunol. 19, 240-246 (2004).

13. Polydorou, O., Pelz, K. \& Hahn, P. Antibacterial effect of an ozone device and its comparison with two dentin-bonding systems. Eur. J. Oral Sci. 114(4), 349-353 (2006).

14. Lynch, E. Evidence-based caries reversal using ozone. J. Esthet. Restor. Dent. 20, 218-222 (2008).

15. Fagrell, T. G., Dietz, W., Lingström, P., Steiniger, F. \& Norén, J. G. Effect of ozone treatment on different cariogenic microorganisms in vitro. Swed. Dent. J. 32(3), 139-147 (2008)

16. Castillo, A. et al. In vitro reduction of mutans streptococci by means of ozone gas application. Quintessence Int. 39(10), 827-831 (2008).

17. Johansson, E., Claesson, R. \& van Dijken, J. W. Antibacterial effect of ozone on cariogenic bacterial species. J. Dent. 37(6), 449-453 (2009).

18. Polydorou, O., Halili, A., Wittmer, A., Pelz, K. \& Hahn, P. The antibacterial effect of gas ozone after 2 months of in vitro evaluation. Clin. Oral Investig. 16(2), 545-550 (2012).

19. Aykut-Yetkiner, A., Eden, E., Ertuğrul, F., Ergin, E. \& Ateş, M. Antibacterial efficacy of prophylactic ozone treatment on patients with fixed orthodontic appliances. Acta Odontol. Scand. 71(6), 1620-1624 (2013).

20. Dukić, W. et al. The efficacy of gaseous ozone on some cariogenic bacteria. Coll. Antropol. 37(1), 109-113 (2013).

21. Kapdan, A., Oztaş, N. \& Sümer, Z. Comparing the antibacterial activity of gaseous ozone and chlorhexidine solution on a tooth cavity model. J. Clin. Exp. Dent. 5(3), e133-e137 (2013).

22. Sadatullah, S., Mohamed, N. \& Razak, F. Qualitative analyses of the antimicrobial effect of ozonated water on supragingival plaque and salivary microbes. Ann. Med. Health Sci. Res. 4(4), 526-531 (2014).

23. Kollmuss, M. et al. Antimicrobial effect of gaseous and aqueous ozone on caries pathogen microorganisms grown in biofilms. Am. J. Dent. 27(3), 134-138 (2014).

24. Anumula, L., Kumar, K. S., Krishna, C. M. \& Lakshmi, K. S. Antibacterial activity of freshly prepared ozonated water and chlorhexidine on mutans streptococcus when used as an oral rinse-a randomised clinical study. J. Clin. Diagn. Res. 11(7), ZCO5-ZCO8 (2017).

25. Makeeva, I. M., Turkina, A. Y., Margaryan, E. G., Paramonov, Y. O. \& Polyakova, M. A. Assessment of antibacterial efficacy of ozone therapy in treatment of caries at the white spot stage. Stomatologiia (Mosk.) 96(4), 7-10 (2017).

26. Ximenes, M. et al. Antimicrobial activity of ozone and NaF-chlorhexidine on early childhood caries. Braz. Oral Res. 31, e2 (2017).

27. Safwat, O., Elkateb, M., Dowidar, K., Salam, H. A. \& El Meligy, O. Microbiological evaluation of ozone on dentinal lesions in young permanent molars using the stepwise excavation. J Clin Pediatr. Dent. 42(1), 11-20 (2018).

28. Dähnhardt, J. E., Jaeggi, T. \& Lussi, A. Treating open carious lesions in anxious children with ozone: a prospective controlled clinical study. Am. J. Dent. 19(5), 267-270 (2006).

29. Libonati, A. et al. Clinical antibacterial effectiveness Healozone Technology after incomplete caries removal. Eur. J. Paediatr. Dent. 20(1), 73-78 (2019).

30. Bocci, V. Scientific and medical aspects of ozone therapy. Arch. Med. Res. 37, 425-435 (2006).

31. Knight, G. M., McIntyre, J. M., Craig, G. G. \& Mulyani Zilm, P. S. The inability of Streptococcus mutans and Lactobacillus acidophilus to form a biofilm in vitro on dentine pretreated with ozone. Aust. Dent. J. 53(4), 349-353 (2008).

32. Yazıcıoğlu, O. \& Ulukap, H. The investigation of non-invasive techniques for treating early approximal carious lesions: an in vivo study. Int. Dent. J. 64(1), 1-11 (2014).

33. Unal, M. \& Oztas, N. Remineralization capacity of three fissure sealants with and without gaseous ozone on non-cavitated incipient pit and fissure caries. J. Clin. Pediatr. Dent. 39(4), 364-370 (2015).

34. Beretta, M. \& Federici Canova, F. A new method for deep caries treatment in primary teeth using ozone: a retrospective study. Eur. J. Paediatr. Dent. 18(2), 111-115 (2017).

35. Oen, K. T. et al. Attitudes and expectations of treating deep caries: a PEARL Network survey. Gen. Dent. 55, 197-203 (2007).

36. Thompson, V., Craig, R. G., Curro, F. A., Green, W. S. \& Ship, J. A. Treatment of deep carious lesions by complete excavation or partial removal: a critical review. J. Am. Dent. Assoc. 139, 705-712 (2008).

37. Ricketts, D. N., Kidd, E. A., Innes, N. \& Clarkson, J. Complete or ultraconservative removal of decayed tissue in unfilled teeth. Cochrane Database Syst. Rev. 3, CD003808 (2006).

38. Kidd, E. A. Clinical threshold for carious tissue removal. Dent. Clin. N. Am. 54, 541-549 (2010).

39. Ersin, N. K., Uzel, A., Aykut, A., Candan, U. \& Eronat, C. Inhibition of cultivable bacteria by chlorhexidine treatment of dentin lesions treated with the ART technique. Caries Res. 40, 172-177 (2006).

40. Takushige, T., Cruz, E. V., Moral, M. A. \& Hoshino, E. Non-surgical treatment of pulpitis, including those with history of spontaneous pain, using a combination of antibacterial drugs. J. LSTR. Therapy 7, 1-5 (2008).

41. Safwat, O., Elkateb, M., Dowidar, K. \& El Meligy, O. Clinical evaluation of ozone on dentinal lesions in young permanent molars using the stepwise excavation. J. Clin. Pediatr. Dent. 41(6), 429-441 (2017).

42. Lima, J. P. et al. Evaluation of the antimicrobial effect of photodynamic antimicrobial therapy in an in situ model of dentine caries. Eur. J. Oral Sci. 117, 568-574 (2009).

43. Huth, K. C. et al. Effect of ozone on oral cells compared with established antimicrobials. Eur. J. Oral Sci. 114(5), 435-440 (2006).

44. Huth, K. C. et al. Effect of aqueous ozone on the NF-kappaB system. J. Dent. Res. 86(5), 451-456 (2007). 
45. Alomiri, M. K., Alhijawi, M. M., AlZarea, B. K., Abul Hassan, R. \& Lynch, E. Ozone treatment of recurrent aphthous stomatitis: a double blinded study. Sci. Rep. 6, 27772 (2016).

46. AlZarea, B. K. Management of denture-related traumatic ulcers using ozone. J. Prosthet. Dent. 121(1), 76-82 (2018).

47. Bocci, V. A., Zanardi, I. \& Travagli, V. Ozone acting on human blood yields a hormetic dose-response relationship. J. Trans. Med. 9, 66 (2011).

48. Srikanth, A., Sathish, M. \& Harsha, A. V. S. Application of ozone in the treatment of periodontal disease. J. Pharm. Bioallied. Sci. 5, S89-S94 (2013).

49. Azuma, K. et al. Anti-inflammatory effects of ozonated water in an experimental mouse model. Biomed. Rep. 2, 671-674 (2014).

50. Kucukgul, A., Erdogan, S., Gonenci, R. \& Ozan, G. Beneficial effects of nontoxic ozone on H2O2-induced stress and inflammation. Biochem. Cell Biol. 94, 577-583 (2016).

51. Alomiri, M. K., Abul Hassan, R., Al Zarea, B. K. \& Lynch, E. Effects of combining ozone and hydrogen peroxide on tooth bleaching: a clinical study. J. Dent. 53, 88-93 (2016).

52. Alomiri, M. K., Al Nazeh, A. A., Kielbassa, A. M. \& Lynch, E. Randomized controlled clinical trial on bleaching sensitivity and whitening efficacy of hydrogen peroxide versus combinations of hydrogen peroxide and ozone. Sci. Rep. 8(1), 2407 (2018).

53. Alomiri, M. K., Lamfon, H. A., Al Nazeh, A. A., Kielbassa, A. M. \& Lynch, E. Randomized clinical trial on the comparison of bleaching outcomes using either ozone or hydrogen peroxide. Quintessence Int. 49(8), 625-634 (2018).

54. Alpert, S. E., Walenga, R. W., Jaspers, I., Qu, Q. \& Chen, L. C. Ozone inactivates cyclooxygenase in human tracheal epithelial cells without altering PGHS-2 mRNA or protein. Am. J. Physiol. 272, L879-887 (1997).

55. Paller, C. J., Campbell, C. M., Edwards, R. R. \& Dobs, A. S. Sex-based differences in pain perception and treatment. Pain Med. 10, 289-299 (2009).

56. Johansson, E., Andersson-Wenckert, I., Hagenbjörk-Gustafsson, A. \& Van Dijken, J. W. Ozone air levels adjacent to a dental ozone gas delivery system. Acta Odontol. Scand. 65, 324-330 (2007).

57. Millar, B. J. \& Hodson, N. Assessment of the safety of two ozone delivery devices. J. Dent. 35(3), 195-200 (2007).

58. Clavo, B. et al. Long-term improvement in refractory headache following ozone therapy. J. Altern. Complement. Med. 19, 453-458 (2013).

59. Bocci, V., Borrelli, E., Zanardi, I. \& Travagli, V. The usefulness of ozone treatment in spinal pain. Drug Des. Devel. Ther. 9, 2677-2685 (2015).

60. Nogales, C. G., Ferrari, P. H., Kantorovich, E. O. \& Lage-Marques, J. L. Ozone therapy in medicine and dentistry. J. Contemp. Dent. Pract. 9, 75-84 (2008).

61. Seidler, V. et al. Ozone and its usage in general medicine and dentistry: a review article. Prague Med. Rep. 109, 5-13 (2008).

62. McKenna, D. F., Borzabadi-Farahani, A. \& Lynch, E. The effect of subgingival ozone and/or hydrogen peroxide on the development of peri-implant mucositis: a double-blind randomized controlled trial. Int. J. Oral Maxillofac. Implants 28, 1483-1489 (2013).

63. Fuccio, C. et al. A single subcutaneous injection of ozone prevents allodynia and decreases the over-expression of pro-inflammatory caspases in the orbito-frontal cortex of neuropathic mice. Eur. J. Pharmacol. 603, 42-49 (2009).

64. Raafat Abdelaziz, R., Mosallam, R. S. \& Yousry, M. M. Tubular occlusion of simulated hypersensitive dentin by the combined use of ozone and desensitizing agents. Acta Odontol. Scand. 69, 395-400 (2011).

65. Gürsoy, H., Çakar, G., İpçi, ŞD., Kuru, B. \& Yilmaz, S. In vitro evaluation of the effects of different treatment procedures on dentine tubules. Photomed. Laser Surg. 30, 695-698 (2012).

66. Atabek, D., Bodur, H., Yalcin, G. \& Kalayci, S. Effects of oxidative irrigants on root dentin structure: Attenuated Total Reflection Fourier Transform Infrared Spectroscopy study. Oral Health Dent. Manag. 13, 753-756 (2014).

67. Agrillo, A., Ungari, C., Filiaci, F., Priore, P. \& Iannetti, G. Ozone therapy in the treatment of avascular bisphosphonate-related jaw osteonecrosis. J. Craniofac. Surg. 18, 1071-1075 (2007).

68. Kazancioglu, H. O., Kurklu, E. \& Ezirganli, S. Effects of ozone therapy on pain, swelling, and trismus following third molar surgery. Int. J. Oral Maxillofac. Surg. 43, 644-648 (2014).

69. Kazancioglu, H. O., Ezirganli, S. \& Demirtas, N. Comparison of the influence of ozone and laser therapies on pain, swelling, and trismus following impacted third-molar surgery. Lasers Med. Sci. 29, 1313-1319 (2014).

70. Durmus, N., Tok, Y. T., Kaya, S. \& Akcay, M. Effectiveness of the ozone application in two-visit indirect pulp therapy of permanent molars with deep carious lesion: a randomized clinical trial. Clin Oral Investig. 23(10), 3789-3799 (2019).

71. Krunić, J. et al. Clinical antibacterial effectiveness and biocompatibility of gaseous ozone after incomplete caries removal. Clin Oral Investig. 23(2), 785-792 (2019).

72. Mese, M., Tok, Y. T., Kaya, S. \& Akcay, M. Influence of ozone application in the stepwise excavation of primary molars: a randomized clinical trial. Clin Oral Investig. 24(10), 3529-3538 (2020).

73. Freeman, R., Holmes, J., Lynch, E. Ozone: a new treatment modality for dentally anxious patients. In: Ozone The revolution in Dentistry (ed. Lynch, E.) 357-364 (Quintessence, 2004)

74. Alomiri, M. K., Abul Hassan, R., AlZarea, B. K. \& Lynch, E. Improved tooth bleaching combining ozone and hydrogen peroxide-a blinded study. J. Dent. 46, 30-35 (2016).

75. Alomiri, M. K., Abul Hassan, R., AlZarea, B. K. \& Lynch, E. Comparison of dental bleaching effects of ozone and hydrogen peroxide. Am. J. Dent. 29, 251-254 (2016).

76. Alomiri, M. K., Abul Hassan, R., Kielbassa, A. M. \& Lynch, E. Bleaching efficacy of ozone/hydrogen peroxide versus hydrogen peroxide/ozone application. Quintessence Int. 48, 783-791 (2017).

77. Mertz-Fairhurst, E. J., Curtis, J. W. Jr., Ergle, J. W., Rueggeberg, F. A. \& Adair, S. M. Ultraconservative and cariostatic sealed restorations: results at year 10. J. Am. Dent. Assoc. 129, 55-66 (1998).

78. Maltz, M., Henz, S. L., de Oliveira, E. F. \& Jardim, J. J. Conventional caries removal and sealed caries in permanent teeth: a microbiological evaluation. J. Dent. 40, 776-782 (2012).

79. Ricketts, D., Lamont, T., Innes, N. P., Kidd, E. \& Clarkson, J. E. Operative caries management in adults and children. Cochrane Database Syst. Rev. 3, CD003808 (2019).

80. Barros, M. M. A. F., De Queiroz Rodrigues, M. I., Muniz, F. W. M. G. \& Rodrigues, L. K. A. Selective, stepwise, or nonselective removal of carious tissue: which technique offers lower risk for the treatment of dental caries in permanent teeth? A systematic review and meta-analysis. Clin Oral Investig. 24(2), 521-532 (2020).

81. Poorterman, J. H., Weerheijm, K. L., Aartman, I. H. \& Kalsbeek, H. Radiographic dentinal caries and its progression in occlusal surfaces in Dutch 17-year-olds: a 6-year longitudinal study. Caries Res. 37, 29-33 (2003).

82. Pedrotti, D. et al. Does selective carious tissue removal of soft dentin increase the restorative failure risk in primary teeth? Systematic review and meta-analysis. J. Am. Dent. Assoc. 150(7), 582-590 (2019).

83. Orhan, A. I., Oz, F. T., Ozcelik, B. \& Orhan, K. A clinical and microbiological comparative study of deep carious lesion treatment in deciduous and young permanent molars. Clin. Oral Investig. 12(4), 369-378 (2008).

\section{Acknowledgements}

The authors thank Mrs M. AbdelAziz for her help during preparation of this manuscript. Thanks also to the University of Jordan and King Khalid University for making this study possible and for providing administrative support. 


\section{Author contributions}

M.K.AL-O. and E.L. conceived the study. M.K.AL-O., E.L., R.A., and A.A.AL. designed the study. M.K.AL-O and R.A. collected the data. M.K.AL-O., R.A., A.A.AL., N.M.Alq., and N.M.Ala. interpreted the data, conceived the results, drafted sections of the manuscript, and revised the manuscript. M.K.AL-O. carried out the data analysis. M.K.AL-O, A.A.AL., N.M.Alq., N.M.Ala., and E.L. critically revised the manuscript. All authors read and approved the submitted final version of the manuscript.

\section{Funding}

This research received no external funding. This research did not receive any specific grant from funding agencies in the public, commercial, or not-for-profit sectors.

\section{Competing interests}

Edward Lynch has been the main researcher for healOzone grants to Universities from Curozone, and Queen's University has sold and assigned the rights for healOzone patents in Edward Lynch's name to Curozone. Edward Lynch does not receive any royalties, and this investigation was not funded (neither by Curozone nor by any other company). The other authors have no conflicts of interests.

\section{Additional information}

Correspondence and requests for materials should be addressed to M.K.A.-O.

Reprints and permissions information is available at www.nature.com/reprints.

Publisher's note Springer Nature remains neutral with regard to jurisdictional claims in published maps and institutional affiliations.

(c) (i) Open Access This article is licensed under a Creative Commons Attribution 4.0 International License, which permits use, sharing, adaptation, distribution and reproduction in any medium or format, as long as you give appropriate credit to the original author(s) and the source, provide a link to the Creative Commons licence, and indicate if changes were made. The images or other third party material in this article are included in the article's Creative Commons licence, unless indicated otherwise in a credit line to the material. If material is not included in the article's Creative Commons licence and your intended use is not permitted by statutory regulation or exceeds the permitted use, you will need to obtain permission directly from the copyright holder. To view a copy of this licence, visit http://creativecommons.org/licenses/by/4.0/.

(c) The Author(s) 2021 